\title{
Opioid Prescribing Practices Among Surgical Providers: The Relationship with Patient-Level Factors: Rural Residency or Cancer Diagnosis
}

Heather F. Thiesset ( $\nabla$ heather.thiesset@hsc.utah.edu )

University of Utah Health https://orcid.org/0000-0002-5484-5303

Lyen $\mathrm{C}$ Huang

University of Utah Health

Karen C Schliep

University of Utah Health

Virginia L Valentin

University of Utah Health

Lisa H. Gren

University of Utah Health

Christina A Porucznik

University of Utah Health

Research article

Keywords:

Posted Date: April 13th, 2020

DOI: https://doi.org/10.21203/rs.3.rs-19237/v1

License: (c) (1) This work is licensed under a Creative Commons Attribution 4.0 International License.

Read Full License 


\section{Abstract}

Background Patients living in rural communities and patients with a cancer diagnosis are two areas potentially overlooked in opioid prescribing clinical decision making that may relate to the amount of overprescribed opioids in the postsurgical environment.

Methods A 35-item questionnaire was administered to surgeons, residents/ fellows (trainees), and advanced practice clinicians (APCs). Descriptive statistics were generated.

Results Surgeons, trainees, and APCs self-reported that they give the same amount of opioids to rural patients as other patients. APCs were more likely to agree that it is easy to e-prescribe (56\%) than surgeons (41\%) and trainees (35\%), so rural patients do not need different consideration. Surgeons (50\%) and trainees $(50 \%)$ agreed compared to APCs $(0 \%)$ that it is easier to give more opioids so a patient does not have get refills if needed for pain. Compared to APCs (5\%), $21 \%$ of surgeons and $45 \%$ of trainees acknowledged giving more opioid narcotics to patients with cancer than patients without a cancer diagnosis.

Conclusions While both groups of prescribing providers reported that they gave the same amount of opioids to rural patients, they differed in their knowledge about e-prescribing and what healthcare access disparities may exist for the rural patient. No differences were reported between provider groups for cancer patients. Responses indicate an opportunity to work with providers to identify potential solutions for improving opioid prescribing practices in rural and cancer patients.

\section{Background}

Opioid overprescribing has been attributed as a major cause of the opioid epidemic currently facing society[1 2]. In the surgical setting, it is estimated that, for common elective procedures, $93.9 \%$ of patients receive opioid prescriptions for pain management at the time of discharge[3]. Pain management is important to support proper patient recovery, but also bears the potential for misuse and abuse of opioid narcotics[4].

Little is known about surgical provider prescribing practices and the pain management needs of patients living in rural communities. Though not surgery specific, Prunuske et al. reported that in general, all types of patients living in rural areas were more likely to be prescribed opioids than a similar adult cohort living in an urban center[5]. They further proposed that rurality is a major indication for overprescribing and needs to be taken into account by prescribing providers[5].

Rural patients have also been shown to be at higher risk for opioid misuse due to socioeconomic factors and prior illicit drug use[6 7]. In fact, it has been estimated that patients living in rural areas are 20-30\% more likely to fatally overdose on opioid narcotics than patients living in an urban setting partially due to demographic factors, but also because of difficulties in access to emergency care facilities and 
services[8]. Prescribing providers have to balance the pain management needs of their patients living in rural areas and their access to care with the high potential for misuse.

Cancer patients are another population warranting additional considerations for postsurgical pain management since their needs tend to involve both acute after surgery pain as well as chronic pain caused by their malignant condition[ 9 10]. It is estimated that $40-50 \%$ of cancer patients have moderate to severe pain during cancer treatment as well as after when they are in remission and beyond[11]. The risk of new and persistent opioid use in opioid-naïve cancer patients is reported to be as high as $10.4 \%$ [11]. Cancer patients are at an increased risk for opioid misuse and potentially fatal outcomes since opioids can increase rates of postoperative infection (which can be detrimental to an immunocompromised cancer patient), venous thromboembolisms, and constipation with subsequent bowel obstructions[12 13].

Prescribing providers' behaviors contribute to overprescribing of opioid narcotics[14 15]. Knowledge of opioid prescribing guidelines and drug monitoring programs can help providers in clinical decision making regarding opioid prescribing for their patients[16]. Pomerleau et al. also reported that surgical providers prescribed opioids in order to improve patient satisfaction scores and accelerate inpatient hospital discharge[15]. Therefore, understanding surgical providers' prescribing behaviors can lead to tailored interventions with the goal to reduce the amount of opioids that are overprescribed. The aim of this study was to understand differences between surgeons, trainees, and advanced practice clinicians (APCs) regarding postsurgical opioid prescribing to populations of rural and cancer patients. Furthermore, we sought to understand which patient demographics influenced providers when prescribing opioids.

\section{Methods}

Study Design

This was a descriptive, cross-sectional survey on provider opioid prescribing, we examined differences in provider's opioid attitudes, perceptions, and practices regarding patients with cancer diagnoses and those living in rural areas. The study was a single-institution study within the University of Utah Health, Department of Surgery between July and September 2018. The study received approval from the University of Utah Institutional Review Board.

\section{Survey}

An anonymous, 35-question instrument including multiple choice and 5-point Likert scale items was developed by an expert committee. Questions were generated based upon anecdotal evidence of prescribing increases in rural and cancer populations and a review of the literature. The questionnaire was then iteratively pilot tested with four volunteer surgeons from multiple disciplines within the target population, who reviewed the questions for content applicability in April 2018. Changes were made based on feedback received and applied to the final questionnaire. During July through September 2018, an electronic link to the web-based REDCap[17] questionnaire was provided to 242 providers (surgeons, 
residents/fellows (trainees), and advanced practice clinicians [APCs]) in nine disciplines at the University of Utah Health Department of Surgery. Disciplines included Abdominal Transplantation and Advanced Hepatobiliary Surgery, Cardiothoracic Surgery, Emergency Medicine, General Surgery, Otolaryngology, Pediatric Surgery, Plastic Surgery, Urology, and Vascular Surgery.

Statistical Analysis

Descriptive statistics were calculated on categorical variables. Univariate analyses were conducted using the chi-squared tests or Fisher's exact test, as appropriate. The primary outcomes were self-reported practices of increased prescribing to patients with cancer or living in a rural location.

Likert scale questions were combined to show agreement ("agree" and "somewhat agree") and disagreement, neutral was kept in a separate category. Frequency statistics compared differences in attitudes, perceptions, and practices by role, age, and time in practice. Prevalence ratios were generated using log-binomial models with surgeons as the reference group for dichotomous variables. Covariates were adjusted on provider age and gender. Data analysis was completed using Stata 15.1 software (College Station, TX).

\section{Results}

A total of $153 / 242$ participants (64\% response rate) responded to the questionnaire, with $86(56 \%)$ surgeons, 31 (20\%) trainees, and 36 (24\%) APCs (Table 1). Most respondents were male (80\%), which is consistent with the target population demographics in the Department of Surgery. APCs and trainees were younger than surgeons (Table 1).

In contrast to each other, prescribing providers (surgeons [95\%], trainees [84\%], and APCs [100\%]) selfreported that compared to urban patients, they give the same amount of opioids to rural patients. However, when questioned further, Trainees acknowledged being more likely to give more opioids to rural patients (Surgeon versus trainee, $\mathrm{PR}=3.9,95 \% \mathrm{Cl}$ 0.4-38.0). Surgeons (96\%), trainees, $(71 \%)$ and APCs $(90 \%)$ all agreed that they worry about rural patients having pain with no open pharmacies on nights and weekends (Figure). APCs were more likely to agree that it is easy to e-prescribe (56\%) than physicians $(41 \%)$ or trainees $(35 \%)$, so rural patients do not need different consideration (Table 2). Surgeons (29\%) and trainees (24\%) were more likely to agree that rural patients have trouble refilling opioid prescriptions because they have to travel long distances than APCs (0\%). Surgeons $(50 \%)$ and trainees $(50 \%)$ agreed to APCs $(0 \%)$ that it is easier to give more opioids so a patient does not have to acquire refills if needed for pain. All groups of providers agreed that it is hard for patients to get in to see providers for opioid refills (Table 2).

When asked about their practice, $5 \%$ of APCs compared to $21 \%$ of surgeons and $45 \%$ of trainees acknowledged giving more opioid narcotics to patients with cancer than non-cancer patients. Trainees were more likely to report giving more opioids in their practice to cancer patients than APCs or surgeons when accounting for age and gender (surgeon versus trainee PR=22.14, 95\% $\mathrm{Cl} 1.8-28.1$ ) (surgeon versus 
APC PR $=0.62,95 \% \mathrm{Cl} 0.05-7.95)$. Providers reported that they either agree or somewhat agree that they are more sympathetic to patients with cancer versus non-cancer patients, surgeons (54\%), trainees $(100 \%)$, and APCs $(62 \%)$. Trainees $(100 \%)$ reported at a higher percentage than either surgeons $(64 \%)$ or APCs (64\%) that cancer patients have the same amount of pain as non-cancer patients. Surgeons (67\%), trainees $(100 \%)$, and APCs $(64 \%)$ either agreed or somewhat agreed that they are worried about opioid addiction in their patients with cancer. Trainees (59\%) and surgeons (43\%) were more likely than APCs $(35 \%)$ to acknowledge that they were more concerned about saving their patient's life than the possibility that they could become addicted to opioids (Table 2).

\section{Discussion}

The current study investigates surgical provider perceptions and beliefs about patients with cancer and patients living in rural areas regarding pain management. We found that providers' do not believe that their prescribing practices change in regards to whether a patient resides in a rural area. However, their knowledge and beliefs regarding potential disparities in access to care and pain management faced by rural patients were different by provider type. Half of surgeons and trainees answered that it is easier for them to give more opioids so a patient does not have to acquire refills when compared to APCs. Surgeons and trainees also answered that their patients do indeed have difficulty getting in to see them for refills due to long distances. These attitudes and beliefs could potentially impact actual prescribing practices by either overprescribing opioids or the reverse by not meeting patient needs. This is similar to previously reported literature that showed rural patients were more likely to have an opioid prescription than similar cohorts in urban areas[6].

While surgeons, trainees, and APCs agreed that cancer patients have the same rates of postoperative pain as their other patients, surgeons and trainees more frequently acknowledged giving more opioid narcotics to patients with cancer in this study. While cancer patients in general have both acute and chronic pain due to their underlying diagnosis and subsequent sequelae, from a surgical perspective, the respondents were in line with what is generally accepted that the surgical pain should be the same regardless of cancer morbidity[10]. However, in 2017, Deshields et al. performed a large study with 301 non-cancer patients (NCP) and 558 cancer patients (CP) and found that NCPs had a higher reported rate of pain when compared to CPs ( $45 \%$ of CP versus $54 \%$ of NCP)[18]. This finding could be due to a higher tolerance for pain from the cancer patient group due to having higher baseline pain due to chronic conditions[18].

This contrast in practice and belief may represent an area for improvement and advocacy and warrants further study to determine if underlying bias or sympathy for cancer patients is affecting actual prescribing practices[11]. This is similar to other studies that found that cancer patients were more likely to have an opioid prescription than a non-cancer patient and that they are at high risk for opioid misuse[911]. 
It is interesting to note that throughout the study, trainees reported similarly in their responses to surgeons when compared to APCs. The structure of resident and fellow training by shadowing and learning under the close supervision of surgeons in an academic medical center[19] would intrinsically be expected to foster similarities between the two groups. While APCs also receive supervision from the surgeons, their attitudes and perceptions differed more frequently from them then did the trainees. This could also argue that the initial medical education from either medical school for residents and fellows or nurse practitioner and physician assistant school has an important role in facilitating attitudes and perceptions regarding opioid prescribing.

This study is potentially limited in its generalizability due to responses being obtained from only one institution and a relatively small population. However, multiple surgical disciplines were surveyed throughout the University of Utah Health system, and there are no institution specific guidelines for opioid prescribing. Further research in a multi-institutional setting is necessary to confirm conclusions; however, it we do not anticipate that the results would not be substantially different across institutions.

Bias from self-reported data is another possible limitation. Surveys were conducted anonymously in order to minimize social desirability bias since there have been studies conducted that suggest that healthcare workers can conform to rules of an institution despite their personal values[20]. We did not suspect that APCs, trainees, and surgeons would not be subject for differential social desirability bias in their reporting.

\section{Conclusion}

While all groups of prescribing providers, surgeons, trainees, and APCs, reported that they gave the same amount of opioids to rural patients that they give to other patients, they differed in their attitudes and perceptions about e-prescribing and potential disparities that exist for the rural patient. This was also the case for cancer patients in that surgeons gave more opioids to cancer patients despite not reporting that they thought cancer patients have more pain than others. Therefore, in regards to rural and cancer patients and potential disparities, there seems to be an opportunity for improvement for prescribing providers with more systematic guidelines and identification of these populations built into the care pathways can lead to individual level discussion in order to evaluate possible barriers and mitigate risk for these patients.

\section{Abbreviations}

APC- Advanced practice clinicians

CP-cancer patients

NCP-non-cancer patients

\section{Declarations}


Ethics approval and consent to participate- This study was approved in accordance with the guidelines and principles of the University of Utah Institutional Review Board and a consent cover letter was utilized. As this was an anonymous survey, documentation of informed consent was not obtained per IRB requirements and approval. It was implied that those who continued with the survey after the consent cover letter gave consent for participation.

Consent for publication- Not applicable.

Availability of data and material- Data and material are available upon request.

Competing interests- There are no competing interests associated with the research presented herein.

Funding- There are no funding sources to declare.

Authors' contributions- HT, LH, KS, VV, LG, CP crafted the research question, hypothesis, and study design. $\mathrm{HT}$ and $\mathrm{LH}$ created the survey. HT, LH, KS, VV, LG, and CP collected the data. HT performed the data analysis while $L H, K S, V V, L G$, and CP provided critical interpretation of the data. HT drafted the manuscript. LH, KS, VV, LG, and CP provided essential revisions to the manuscript. All authors have read and approved the manuscript.

Acknowledgements-Not applicable

\section{References}

1. Makary Ma Fau - Overton HN, Overton Hn Fau -. Wang P, Wang P. Overprescribing is major contributor to opioid crisis. (1756-1833 (Electronic)).

2. Clark DJ, Schumacher MA. America's Opioid Epidemic: Supply and Demand Considerations. (15267598 (Electronic)).

3. Thiels CA. Anderson Ss Fau - Ubl DS, Ubl Ds Fau - Hanson KT, et al. Wide Variation and Overprescription of Opioids After Elective Surgery. (1528 - 1140 (Electronic)).

4. Nimmo SM, Foo ITH, Paterson HMA-Ohoo. Enhanced recovery after surgery: Pain management. (1096-9098 (Electronic)).

5. Prunuske Jp Fau - St Hill CA. St Hill Ca Fau - Hager KD, Hager Kd Fau - Lemieux AM, et al. Opioid prescribing patterns for non-malignant chronic pain for rural versus non-rural US adults: a population-based study using 2010 NAMCS data. (1472-6963 (Electronic)).

6. Cochran GT, Engel RJ, Hruschak VJ, Tarter RE. Prescription Opioid Misuse Among Rural Community Pharmacy Patients: Pilot Study for Screening and Implications for Future Practice and Research. (1531-1937 (Electronic)).

7. Monnat SM, Rigg KK. Examining Rural/Urban Differences in Prescription Opioid Misuse Among US Adolescents. (1748 - 0361 (Electronic)). 
8. Mosher H, Zhou Y, Thurman AL, Sarrazin MV, Ohl ME. Trends in Hospitalization for Opioid Overdose among Rural Compared to Urban Residents of the United States, 2007-2014. (1553-5606 (Electronic)).

9. Liang Y, Bao G, Gong L, et al. Evaluating the analgesic effect and advantage of transcutaneous electrical acupoint stimulation combined with opioid drugs for moderate to severe cancer-related pain: a study protocol for a randomized controlled trial. (1745-6215 (Electronic)).

10. Fradkin M, Batash R, Elamleh S, et al. Management of peripheral neuropathy induced by chemotherapy. LID - 10.2174/0929867326666190107163756 [doi]. (1875-533X (Electronic)).

11. Bennett M, Paice JA, Wallace M. Pain and Opioids in Cancer Care: Benefits, Risks, and Alternatives. (1548-8756 (Electronic)).

12. Lee JS, Hu HM, Edelman AL, et al. New Persistent Opioid Use Among Patients With Cancer After Curative-Intent Surgery. (1527-7755 (Electronic)).

13. Cozowicz C, Olson A, Fau - Poeran J, Poeran J, Fau - Morwald EE, et al. Opioid prescription levels and postoperative outcomes in orthopedic surgery. (1872-6623 (Electronic)).

14. Cheatle MD. The Impact of Prescription Drug Monitoring Programs and Prescribing Guidelines on Opioid Prescribing Behaviors: A Time for Institutional and Regulatory Changes. (1526-4637 (Electronic)).

15. Pomerleau AC, Nelson LS, Hoppe JA, Salzman M, Weiss PS, Perrone J. The Impact of Prescription Drug Monitoring Programs and Prescribing Guidelines on Emergency Department Opioid Prescribing: A Multi-Center Survey. (1526-4637 (Electronic)).

16. Leichtling GJ, Irvine JM, Hildebran C, Cohen DJ, Hallvik SE, Deyo RA. Clinicians' Use of Prescription Drug Monitoring Programs in Clinical Practice and Decision-Making. (1526-4637 (Electronic)).

17. Harris PA, Taylor R, Fau - Thielke R, Thielke R, Fau - Payne J, Payne J, Fau - Gonzalez N, Gonzalez N, Fau - Conde JG, Conde JG. Research electronic data capture (REDCap)--a metadata-driven methodology and workflow process for providing translational research informatics support. (1532 0480 (Electronic)).

18. Deshields TL, Penalba V, Liu J, Avery J. Comparing the symptom experience of cancer patients and non-cancer patients. (1433-7339 (Electronic)).

19. Surgery D. Residencies and Fellowships. Secondary Residencies and Fellowships 2019. .

20. Hermann $\mathrm{H}$, Trachsel M, Biller-Andorno N. Physicians' personal values in determining medical decision-making capacity: a survey study. (1473-4257 (Electronic)).

\section{Tables}

Table 1: Demographics, by role 


\begin{tabular}{|c|c|c|c|}
\hline & Surgeons $(n=86)$ & Trainees $(n=31)$ & APCs $(n=36)$ \\
\hline \multicolumn{4}{|c|}{ Gender } \\
\hline Male & $69(80 \%)$ & $20(65 \%)$ & $12(34 \%)$ \\
\hline Female & $17(20 \%)$ & $11(35 \%)$ & $23(66 \%)$ \\
\hline \multicolumn{4}{|c|}{ Age } \\
\hline $20-29$ & 0 & $4(13 \%)$ & $10(29 \%)$ \\
\hline $30-39$ & $22(26 \%)$ & $27(87 \%)$ & $11(31 \%)$ \\
\hline $40-49$ & $39(44 \%)$ & 0 & $7(20 \%)$ \\
\hline $50-59$ & $19(21 \%)$ & 0 & $4(11 \%)$ \\
\hline$>60$ & $7(9 \%)$ & 0 & $3(9 \%)$ \\
\hline \multicolumn{4}{|c|}{ Years in practice } \\
\hline$<5$ & $26(30 \%)$ & $\mathrm{n} / \mathrm{a}$ & $12(40 \%)$ \\
\hline $5-9$ & $16(19 \%)$ & $\mathrm{n} / \mathrm{a}$ & $9(30 \%)$ \\
\hline $10-20$ & $28(32 \%)$ & $\mathrm{n} / \mathrm{a}$ & $5(17 \%)$ \\
\hline$>20$ & $16(19 \%)$ & $\mathrm{n} / \mathrm{a}$ & $4(13 \%)$ \\
\hline
\end{tabular}

Table 2: Comparison survey respondents, by role 


\begin{tabular}{|c|c|c|c|c|}
\hline \multicolumn{5}{|c|}{ Attitudes/ perceptions } \\
\hline & & $\begin{array}{l}\text { Surgeons } \\
(\mathrm{n}=86)\end{array}$ & $\begin{array}{l}\text { Trainees } \\
(\mathrm{n}=31)\end{array}$ & $\mathrm{APC}(\mathrm{n}=36)$ \\
\hline \multirow{3}{*}{$\begin{array}{l}\text { Please rate your agreement with the following statement: "I } \\
\text { worry about patients having pain on nights/weekends when } \\
\text { they can't get open pharmacies"? }\end{array}$} & Agree & $16(33 \%)$ & $6(19 \%)$ & $6(30 \%)$ \\
\hline & Somewhat agree & $30(63 \%)$ & $16(52 \%)$ & $12(60 \%)$ \\
\hline & Do not agree & $2(4 \%)$ & $9(29 \%)$ & $2(10 \%)$ \\
\hline \multirow{3}{*}{$\begin{array}{l}\text { Please rate your agreement with the following statement: "It is } \\
\text { hard for patients to get in to see providers for follow up and } \\
\text { opioid prescription refills"? }\end{array}$} & Agree & $13(27 \%)$ & $8(38 \%)$ & $4(27 \%)$ \\
\hline & Somewhat agree & $32(67 \%)$ & $12(57 \%)$ & $9(60 \%)$ \\
\hline & Do not agree & $3(6 \%)$ & $1(5 \%)$ & $2(13 \%)$ \\
\hline \multirow{3}{*}{$\begin{array}{l}\text { Please rate your agreement with the following statement "It is } \\
\text { easy to e-prescribe so patients don't need extra } \\
\text { considerations in rural settings"? }\end{array}$} & Agree & $24(41 \%)$ & $8(35 \%)$ & $18(56 \%)$ \\
\hline & Somewhat agree & $25(42 \%)$ & $13(57 \%)$ & $12(38 \%)$ \\
\hline & Do not agree & $10(17 \%)$ & $2(8 \%)$ & $2(6 \%)$ \\
\hline \multirow{3}{*}{$\begin{array}{l}\text { Please rate your agreement with the following statement: } \\
\text { "Rural patients have trouble refilling opioid prescriptions } \\
\text { because they have to travel long distances?" }\end{array}$} & Agree & $12(29 \%)$ & $7(24 \%)$ & 0 \\
\hline & Somewhat agree & $28(66 \%)$ & $11(38 \%)$ & $11(79 \%)$ \\
\hline & Do not agree & $2(5 \%)$ & $11(38 \%)$ & $3(21 \%)$ \\
\hline \multirow{3}{*}{$\begin{array}{l}\text { Please rate your agreement with the following statement: "It is } \\
\text { easier to give more opioids so a patient doesn't have to deal } \\
\text { with getting refills if needed for pain"? }\end{array}$} & Agree & $13(50 \%)$ & $4(50 \%)$ & 0 \\
\hline & Somewhat agree & $11(42 \%)$ & $4(50 \%)$ & $4(80 \%)$ \\
\hline & Do not agree & $2(8 \%)$ & 0 & $1(20 \%)$ \\
\hline \multirow{3}{*}{$\begin{array}{l}\text { I am more sympathetic to patients with cancer who are in } \\
\text { pain than non-cancer patients in pain }\end{array}$} & Agree & $7(17 \%)$ & $7(32 \%)$ & $5(24 \%)$ \\
\hline & Somewhat agree & $16(38 \%)$ & $15(68 \%)$ & $8(38 \%)$ \\
\hline & Do not agree & $19(45 \%)$ & 0 & $8(38 \%)$ \\
\hline \multirow{3}{*}{$\begin{array}{l}\text { Patients with cancer have more pain than other non-cancer } \\
\text { patients }\end{array}$} & Agree & $6(14 \%)$ & $3(19 \%)$ & $4(24 \%)$ \\
\hline & Somewhat agree & $22(50 \%)$ & $13(81 \%)$ & $7(41 \%)$ \\
\hline & Do not agree & $16(36 \%)$ & 0 & $6(35 \%)$ \\
\hline \multirow{3}{*}{$\begin{array}{l}\text { I am worried about opioid addiction in my patients with } \\
\text { cancer }\end{array}$} & Agree & $16(25 \%)$ & $12(52 \%)$ & $7(25 \%)$ \\
\hline & Somewhat agree & $27(42 \%)$ & $11(48 \%)$ & $11(39 \%)$ \\
\hline & Do not agree & $21(33 \%)$ & 0 & $10(36 \%)$ \\
\hline \multirow{3}{*}{$\begin{array}{l}\text { I am more concerned with saving my patient's life than the } \\
\text { possibility of them being addicted to opioids }\end{array}$} & Agree & $22(43 \%)$ & $13(59 \%)$ & $8(35 \%)$ \\
\hline & Somewhat agree & $18(35 \%)$ & $7(32 \%)$ & $13(57 \%)$ \\
\hline & Do not agree & $11(22 \%)$ & $2(9 \%)$ & $2(8 \%)$ \\
\hline \multicolumn{5}{|c|}{ Practices } \\
\hline \multirow{3}{*}{$\begin{array}{l}\text { What is your practice towards patients with cancer and } \\
\text { prescribing opioid narcotics? }\end{array}$} & I give more & $12(21 \%)$ & $14(45 \%)$ & $1(5 \%)$ \\
\hline & I give the same & $46(79 \%)$ & $17(55 \%)$ & $19(95 \%)$ \\
\hline & I give fewer & 0 & 0 & 0 \\
\hline \multirow{3}{*}{$\begin{array}{l}\text { How does your opioid prescribing practice change when you } \\
\text { have a patient seeing you who lives in a rural area? }\end{array}$} & I give more pills & $4(5 \%)$ & $5(16 \%)$ & 0 \\
\hline & I give the same & $76(95 \%)$ & $26(84 \%)$ & $34(100 \%)$ \\
\hline & I give fewer pills & 0 & 0 & 0 \\
\hline
\end{tabular}

\section{Figures}




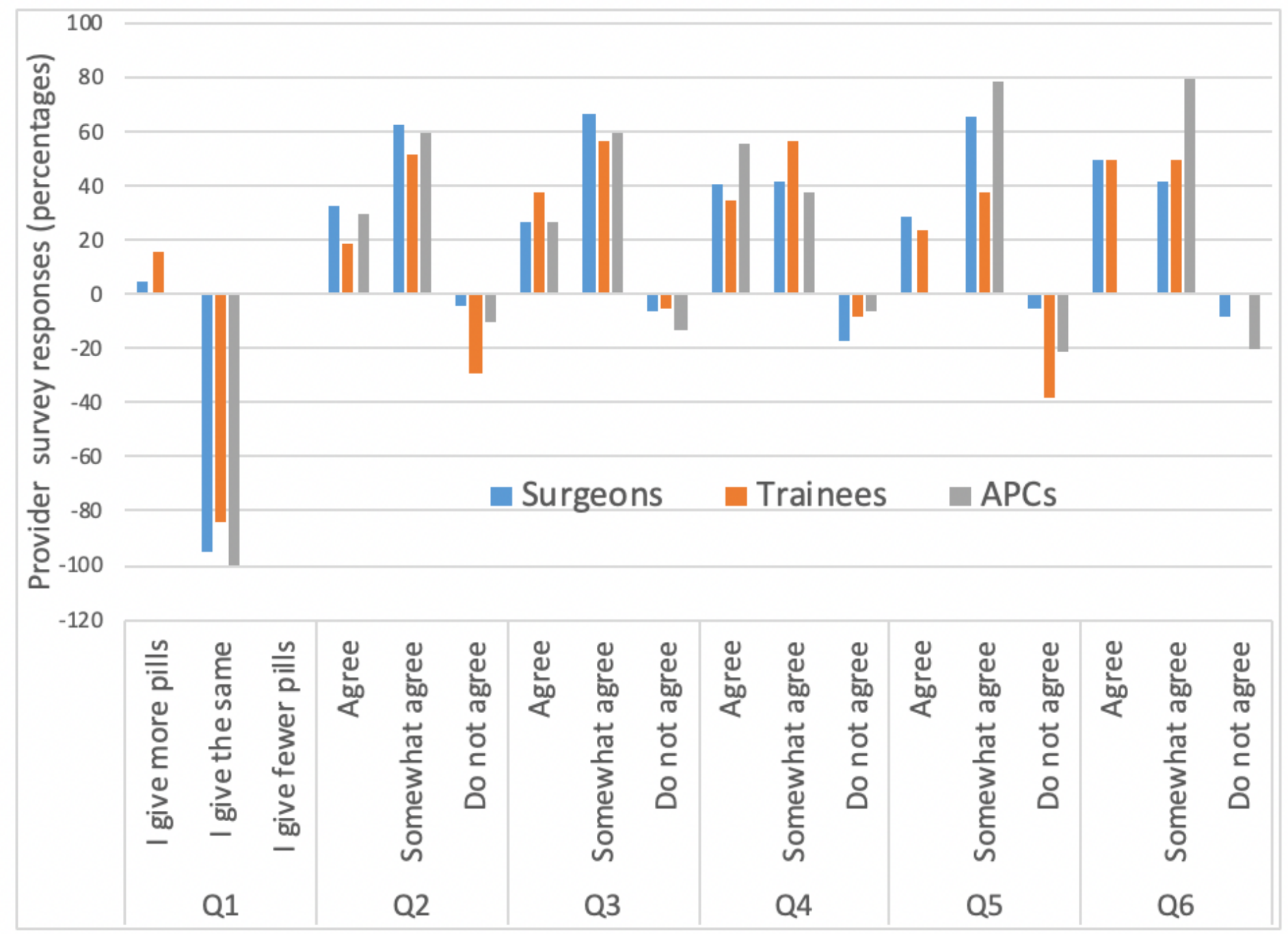

Figure 1

Provider perceptions regarding rural patients and opioids, by role. Q1. How does your opioid prescribing practice change when you have a patient seeing you who lives in a rural area? Q2. Please rate your agreement with the following statement: "I worry about patients having pain on nights/weekends when they can't get open pharmacies"? Q3. Please rate your agreement with the following statement: "It is hard for patients to get in to see providers for follow up and opioid prescription refills"? Q4. Please rate your agreement with the following statement "It is easy to e-prescribe so patients don't need extra considerations in rural settings"? Q5. Please rate your agreement with the following statement: "Rural patients have trouble refilling opioid prescriptions because they have to travel long distances?" Q6. Please rate your agreement with the following statement: "It is easier to give more opioids so a patient doesn't have to deal with getting refills if needed for pain"? 